University of Nebraska - Lincoln

DigitalCommons@University of Nebraska - Lincoln

Sociology Department, Faculty Publications

Sociology, Department of

$1-2011$

\title{
Watching the Detectives: Crime Programming, Fear of Crime, and Attitudes about the Criminal Justice System
}

Lisa A. Kort-Butler

University of Nebraska-Lincoln, Ikortbutler2@unl.edu

Kelley J. Sittner Hartshorn

University of Nebraska-Lincoln, kelley.sittner@okstate.edu

Follow this and additional works at: https://digitalcommons.unl.edu/sociologyfacpub

Part of the Criminology Commons

Kort-Butler, Lisa A. and Sittner Hartshorn, Kelley J., "Watching the Detectives: Crime Programming, Fear of Crime, and Attitudes about the Criminal Justice System" (2011). Sociology Department, Faculty

Publications. 181.

https://digitalcommons.unl.edu/sociologyfacpub/181

This Article is brought to you for free and open access by the Sociology, Department of at DigitalCommons@University of Nebraska - Lincoln. It has been accepted for inclusion in Sociology Department, Faculty Publications by an authorized administrator of DigitalCommons@University of Nebraska - Lincoln. 


\title{
Watching the Detectives: Crime Programming, Fear of Crime, and Attitudes about the Criminal Justice System
}

\author{
Lisa A. Kort-Butler and Kelley J. Sittner Hartshorn \\ University of Nebraska-Lincoln \\ Corresponding author - Lisa A. Kort-Butler, Department of Sociology, 711 Oldfather Hall, \\ University of Nebraska-Lincoln, PO Box 880324, Lincoln, NE 68588-0324; email Ikortbutler2@unl.edu
}

\begin{abstract}
Research demonstrates a complex relationship between television viewing and fear of crime. Social critics assert that media depictions perpetuate the dominant cultural ideology about crime and criminal justice. This article examines whether program type differentially affects fear of crime and perceptions of the crime rate. Next, it tests whether such programming differentially affects viewers' attitudes about the criminal justice system, and if these relationships are mediated by fear. Results indicated that fear mediated the relationship between viewing nonfictional shows and lack of support for the justice system. Viewing crime dramas predicted support for the death penalty, but this relationship was not mediated by fear. News viewership was unrelated to either fear or attitudes. The results support the idea that program type matters when it comes to understanding people's fear of crime and their attitudes about criminal justice.
\end{abstract}

$\mathrm{R}$ esearch has addressed how media consumption in its various forms-newspapers, television news, and crime dramas-influences viewers' perceptions of crime in their social worlds, their level of concern or fear of victimization, and their attitudes about the criminal justice system. Previous research has also emphasized how variations in content across program types may differentially affect viewers' perceptions. Although attention has been given to the impact of television news, network crime dramas, and reality shows like "COPS" and "America's Most Wanted," less attention has been given to the nonfictional documentary style programming aired by network stations and proliferated on cable channels. Shows like ABC's "Primetime," A \& E's “The First 48," and Discovery's “The New Detectives" use dramatic elements, peppered with interviews of criminal justice personnel, victims, offenders, witnesses, and academic experts, to tell stories about a particular criminal event or series of events. In fact, there is now an entire channel dedicated to this kind of programming, ID: Investigation Discovery. Unlike "COPS," these kinds of shows, when they do follow the police, usually follow detectives or forensic analysts as they try to solve a mystery. Unlike "America's Most Wanted," they do not engage the viewer in finding the alleged offender. As an emerging 
genre in its own right, nonfictional documentary-style programming further blurs the line between crime reporting as done by the news media and fictional crime dramas like "CSI: Crime Scene Investigation" (Cavender and Deutch 2007). A description of the series "Watching the Detectives," which airs on Biography Channel, highlights this point:

What's the inspiration behind legendary television crime series like NYPD Blue and Law \& Order? It's the extraordinary, dramatic, often hair-raising true tales of New York City detectives. Now for the first time, hard-boiled, street savvy, larger-than-life veteran detectives of the NYPD are coming forward to relive the most unbelievable, entertaining, and often shocking cases of their careers. They've seen it all on the streets of New York and they're ready to share their unflinching first-hand accounts. (Biography Channel 2009)

The question remains regarding whether nonfictional documentary style crime programming affects viewers' level of fear about crime and attitudes about criminal justice and how this may differ from other crime show formats. To address this question, the current article builds on the body of research that has linked media viewership, fear of crime, and attitudes about the criminal justice system. In particular, we focus on four program types: local news, national news, crime dramas, and nonfictional documentary-style crime shows. Although previous research has tested the relationship between program type and fear of crime (Eschholz, Chiricos, and Gertz 2003) and the mediating effect of fear between viewership and attitudes about criminal justice (Dowler 2003), little research has done both.

In this article, we outline the research on television exposure and fear of crime. Then, we describe crime shows as sources of infotainment, in which viewers learn about crime in a context that may amplify fears. In particular, we highlight the emerging genre of nonfictional documentary-style shows as a program type distinct from dramas and reality shows. Finally, we discuss how crime-related programming serves the ideological function of supporting the dominant views about crime and justice issues. Using data from a random sample of adults, the analyses explored how viewing the different types of crime-related programming influenced viewers' fear of crime, their perceptions about the criminal justice system, and their support for the death penalty. We also examined whether fear of crime mediated the relationship between viewing certain program types and attitudinal outcomes.

\section{LITERATURE REVIEW}

\section{Television Exposure and Fear of Crime}

Modern research on the impact of television exposure and crime began with the Cultural Indicators Project (Signorielli, Gerbner, and Morgan 1995). These researchers, led by George Gerbner, forwarded the "cultivation hypothesis," asserting that heavy television viewing engenders fear, mistrust, and perceptions that the world is a dangerous place (Gerbner 1970; Gerbner and Gross 1976). The result, according to Gerbner and Gross (1976), is increased compliance with and reliance on governmental authority, as well as legitimization of social control policies. 
However, as research has progressed, it has revealed that the relationship between television consumption and fear of crime is more complex than initially posited in the cultivation literature. Some studies have noted a correlation between television viewing and fear or anxiety about crime; others have not (Eschholz 1997; Ditton et al. 2004; Doyle 2006). From their review of the research, Heath and Gilbert concluded that "at least some television programming is correlated with fear of crime for at least some of the viewers" (Heath and Gilbert 1996: 380). Such inconsistencies stimulated so-called reception research (e.g., Dahlgren 1988), in which audience characteristics and program characteristics are considered key variables in understanding viewership effects (Eschholz 2003). For example, studies that examine news programming and fear of crime find some relationship between media consumption and fear, but the strength of this relationship varies (Chiricos, Eschholz, and Gertz 1997; Chiricos, Padgett, and Gertz 2000; Weitzer and Kubrin 2004). Factors like type of programming, the messages within the programming (e.g., the degree of "justice" evident in the program), and audience characteristics all complicate the relationship (Heath and Gilbert 1996; Eschholz et al. 2003).

Of particular interest in this article is program type. Program type may differentially affect fear for several reasons outlined by Eschholz et al. (2003). Program characteristics associated with greater effects on fear include higher levels of violence, realistic depictions of crimes, and greater proximity of the criminal event to the viewer, such as an event reported in someone's neighborhood. In contrast, the portrayal of a just resolution to the criminal activity may serve to reduce fear. Accordingly, Eschholz et al. (2003) found that viewing national news and news magazine programs, which have lower levels of violence and proximal relevance, as well as muted realism, was unrelated to fear of crime. On the other hand, viewing local news, which has greater realism, proximate relevance, and a focus on serious crime, was related to fear. Crime dramas and reality crime shows were also linked to fear. Both kinds of programs have high levels of violence, and reality programs clearly offer high levels of realism. Interestingly, although both kinds of programs usually feature resolution, the resolution element did not appear to outweigh the other elements to negate fear. Eschholz et al. (2003) suggested that violence may be the most important element in producing fear, given its presence in all forms of programming that were related to fear.

Fearfulness is relevant because it is considered to be one mechanism by which the media shape public discourse about criminal justice policy (Warr 2000; Cavender 2004). Using data from the National Opinion Survey on Crime and Justice Dowler (2003) noted that crime program viewing (type not specified) was related to fear of crime, and that fear was related to both punitive attitudes and less confidence in police effectiveness. In contrast, using data from Indiana that asked respondents about several media sources, Grabe and Drew (2007) found little evidence that any form of media was consistently related to perceptions and opinions about crime and justice. Although a direct relationship between media consumption in general and fear of crime is equivocal, there appears to be a relationship among watching crime-related television, fear, and support 
for more crime control and punitive measures, particularly when audience reception characteristics are considered (Eschholz 2003; Surette 2003; Doyle 2006).

\section{Crime Programming as Infotainment}

In an expanding television universe that allows people to be more selective in their viewing habits, program type is an increasingly salient area for study. The emergence of a genre dedicated to nonfictional documentary style crime programming has added to people's ability to gather more information about crime. This genre of programs, in format, falls somewhere between crime dramas and reality shows. In their study of "America's Most Wanted" and "Unsolved Mysteries," Cavender and Bond-Maupin (1993) concluded that these nonfiction programs were similar to crime dramas in their overdramatization of crime and in their exaggerations of uncertainty and lack of safety. In reciprocal fashion, dramatic series like "Law \& Order" create a sense of realism by using production techniques originally developed on shows like "America's Most Wanted" (Cavender, Bond-Maupin, and Jurik 1999). Dramas tap into, then sensationalize, current headlines (Eschholz, Mallard, and Flynn 2004). The headlines, which may be hundreds of miles away from the viewer, are developed into personalized narratives, thus making a distant issue more proximal to the viewer (Gans-Boriskin and Wardle 2005).

Contemporary documentary style programs are similar to shows like "America's Most Wanted" and "Unsolved Mysteries," in conveying a sense of reality while portraying the dramatic (Cavender 1998). Documentary style programs, by their nature, require collaboration between criminal justice agents and media organizations (Cavender and Fishman 1998). These programs describe real events, but they incorporate dramatic techniques, like reenactments, narration and music, emotional hooks, and cliffhangers before commercials. In addition to the use of dramatic reenactments, such shows intertwine factual reports with "rumor and speculation," blurring the distinction between news and entertainment, what some call "infotainment" (Sacco 1995:145). The factual information about a crime is supplemented with, and enhanced by, fictionalized recreations (Doyle 1998). Evidence of a continued reciprocity between drama and documentary can be seen in programs like Investigation Discovery's "Forensics: You Decide," which invites viewers to draw conclusions about a real case based on the presentation of actual forensic evidence, just as the viewer is invited to do in forensics-based dramas like "CSI: Crime Scene Investigation."

One distinction between contemporary nonfiction shows and their predecessors is that they generally document only one or two stories during the 30 - or 60 -minute time slot. Contemporary shows align with what Surette (2003) describes as infotainment-news shows, dramatized programs disguised as in-depth reporting. Common threads include: a focus on serious or unusual crimes, a reliance on interviews with real-life participants and experts, and the unfolding of a narrative that follows the investigation and apprehension (Donovon 1998). For example, the description of "The First 48" reads: 
For homicide detectives, the clock starts ticking the moment they are called. Their chance of solving a case is cut in half if they don't get a lead in THE FIRST 48. Each passing hour gives suspects more time to flee, witnesses more time to forget what they saw, and crucial evidence more time to be lost forever. THE FIRST 48 follows detectives from around the country during these first critical hours as they race against time to find the suspect. Gritty and fast-paced, it takes viewers behind the scenes of real-life investigations with unprecedented access to crime scenes, autopsies, forensic processing, and interrogations. (A\&E Television 2009)

Donovon (1998) points out the tendency of the nonfictional format toward populism, in which the narrative of the story portrays "viewer-citizens" who are "collectively, universally, and uniformly hailed as 'tired of crime" " (p. 128). The result is that, like ripped-fromthe-headlines dramas, the distant becomes personal. Considering the research on news, crime dramas, and reality shows, to the extent that nonfictional documentary style shows have high levels of violence, realism, and faux-proximity, viewership should be associated with greater fear of crime. Yet the unique nature of these programs suggests that viewership may have a relationship with fear of crime and criminal justice attitudes that is distinct from news and dramas.

\section{Crime Programming as Ideology}

Scholars recognize that the media, television in particular, is a way through which cultural images about crime are disseminated and reinforced and through which criminal justice policy debates are shaped (Barlow, Barlow, and Chiricos 1995; Sacco 1995; Eschholz et al. 2003; Cavender 2004). Most people have little to no direct experience with crime and therefore must rely on other sources for information about crime and related issues (Barak 1994; Chermak 1994; Surette 2003). The media is the public's primary frame of reference for issues of crime and control, focusing attention on certain events and offering interpretations for how to understand them (Barak 1994; Eschholz 1997). For instance, the dominant theme in crime dramas is "justice" - capturing and punishing the offender-while implying that the only way to deal with offenders is incarceration (Eschholz et al. 2004). Likewise, nonfictional reality crime programs are informed by the conservative ideologies that support justice-based crime control policies (Cavender and Fishman 1998).

According to Altheide (1997), the process of problem framing in the news media informs the audience that some situation is undesirable, that many people are affected by it, and that the main contributing factors are identifiable. Further, the media suggests the "problem" can be changed, that mechanisms exist to change it, and that we (as a society) already have an agent and process in place to fix the problem, usually the government. In short, the discourse of fear that pervades the media encourages public reliance on formal social control (Altheide and Michalowski 1999). When it comes to the problem of crime, the media help to frame the notion that crime is a major problem for everyone, criminality results from individual characteristics, and that we can change the problem through enhancing the social control procedures already in place (Cavender and Fishman 1998; Surette 1998). As a result, it is difficult to "separate the perception of crime and the reac- 
tion to crime" (Barak 1994:32). Observing the changes in crime news and drama beginning in the 1970s and continuing to the present, Cavender (2004) contended:

$[\mathrm{N}]$ ews and drama produced a kind of informational flow about crime. There also were parallel responses to the crime problem across news and drama: it was a visceral, 'get tough' approach. ... As this response was replayed in the coverage of legislative debates across the states, and in movies and TV drama, it eventually became THE solution; and, it became common sense. (P. 346) Describing why there is a lack of association between crime and incarceration rates,

Lyons and Scheingold (2000) suggested that punitive policy shifts are driven by the electoral needs of politicians. Further, the politicized nature of crime and punishment is situated in political discourse and public response, a relationship primarily mediated by the media (Lyons and Scheingold 2000). For instance, Lowry, Nio, and Leitner (2003) found that network news coverage of crime explained more of the variance in the public opinion ranking of crime-as-the-most-important-problem than did the actual UCR crime rate. Kappeler and Potter (2005) argued that the media is a powerful source of myths about crime and justice. These myths perpetuate cultural meanings about crime, offenders, victims, and social control. Ultimately, if the public accepts these myths, the various needs of the crime-industrial complex, government social control agencies, and the media are met. In other words, various groups have a vested interest in the public's continuing concern about crime in order to maintain viewership (in the case of the media) and to maintain public support for a punitive, criminal justice-oriented approach to dealing with the social problem of crime.

Gerbner (1970) asserted that the perceptions and feelings cultivated by television have consequences not only for people's social relationships, but also great potential to shape social policy in general and social control in particular. Indeed, as Altheide (2009) argued, fear is the driving emotion behind shifts in crime control and government intervention efforts. Research that looks directly at the political effects of presumed public response to crime "waves" (i.e., fear) indicates that such fears can promote political shifts (Doyle 2006). Fear is not a conspiracy but a convergence of goals, including politicians seeking an issue, the punitive tendencies of the American public, the content of the news and other media, and the professional motivations of the crime-industrial complex (Surette 1994). In sum, perceptions about and fear of crime represent key mechanisms by which television can shape opinions about criminal justice policy.

\section{THE CURRENT STUDY}

In general, if it is the case that crime-related programming, including news, dramas, and nonfiction documentary style shows, supports the prevailing criminal justice ideology, then it should be directly associated with support for the criminal justice system and support for policies like the death penalty. Moreover, if crime-related programming functions to maintain or perpetuate concern or fear about crime, then it should be indirectly associated with criminal justice attitudes via its effect on fear. In this study, we explored whether the type of 
programming people watch differentially influences their fears about crime and their perceptions of the crime rate, comparing local and national news, crime dramas, and nonfictional documentary style programming. Then, we explored whether the program type influences people's support for the criminal justice system and their support for the harshest criminal justice policy, the death penalty. Finally, we examined whether fear mediates the relationship between program type and these attitudes about the criminal justice system.

\section{METHODS}

\section{Sample}

The data used in this study come from the 2007 Nebraska Annual Social Indicator Survey (NASIS), which is a joint effort of the University of Nebraska-Lincoln Bureau of Sociological Research, the Department of Sociology at the University of Nebraska- Lincoln, and a variety of public agencies. The survey is conducted using Computer- Assisted Telephone Interviewing (CATI) by interviewers well-trained in CATI procedures.

The sample of respondents is drawn from a population consisting of noninstitutionalized persons ages 19 and older in households with telephones, who resided in the State of Nebraska during the survey period (February 2008 to August 2008). The sample comes from a directory-listed sample of telephone numbers in Nebraska. The sample includes telephone numbers for individuals and households who have a landline telephone number published within Nebraska telephone directories. The adult in the household with whom the interviewer was to speak was randomly selected from among all eligible respondents in the household by asking the person who answered the telephone for the number of adults living in the household, and, based on random selection by the computer, requesting to speak with the adult who is of a certain age category (e.g., youngest, oldest, middle).

The sample was 94.8 percent white, 41 percent male, with a mean age of 54.8 , a median household income of $\$ 50,000$ to $\$ 59,000$, and less than a four-year college education. The original sample size was 879 , and final sample size after listwise deletion of missing cases was 784 .

\section{Measures}

The first dependent variable, support for the criminal justice system, was assessed with two dimensions measuring attitudes about the justice system. The first dimension, confidence, was measured with three questions: "How confident are you that the criminal justice system can reduce crime"; "How confident are you that police can protect society from violent crimes"; and "How confident are you that police can protect society from property crimes?" Response options ranged from 0 (not at all confident) to 3 (very confident). The second dimension, fairness, was measured with three questions: "How fair is the treatment by the justice system of people accused of committing a crime"; "How fair is treatment by the justice system of people victimized"; "How fair is the application of the death penalty 
by the justice system?" Responses ranged from 0 (not at all fair) to 3 (very fair). Exploratory factor analysis indicated that these six items loaded onto a single factor. An overall indicator of support for the criminal justice system was created by averaging responses to the six questions, with a Cronbach's alpha of 0.73 .

The second dependent variable, support for the death penalty, was assessed with one question. The respondent was asked: "If you could choose among the following approaches, which do you think is the best penalty for murder?" The response options were prison with the possibility of parole once the offender has reformed, life in prison without the possibility of parole, and death penalty. The variable was coded so that 1 equaled death penalty support, and the other categories were zero.

Two variables measured the frequency with which respondents watch television programming related to crime in an average week. Days watch TV crime drama was measured with the item "How many days in an average week do you watch TV crime dramas like 'Law and Order' or 'CSI'?" Days watch crime non-fiction was assessed with the item "How many days in an average week do you watch nonfictional programs about crime, like those on ABC's 'Primetime', CourtTV, or the Discovery Channel?" In addition, two variables measured the frequency with which respondents may have been exposed to information about crime on television news. Days watch local news was assessed by asking respondents the number of days in an average week they watched any of the local news programs in their area. Similarly, days watch national news was measured by asking respondents the number of days in an average week they watched national network news programs or cable news channels. For all these items, responses ranged from 0 (zero days per week) to 7 (every day of the week).

Fear of crime was assessed with six questions regarding how often respondents personally worried about being victimized, including worry about walking alone at night, getting robbed, having their residence broken into, being sexually assaulted, getting murdered, and having someone in his/her family becoming a victim of a crime. Response options ranged from 0 (never) to 4 (almost always). Responses to the six items were averaged into an overall indicator of fear. Cronbach's alpha equaled 0.82. This scale is similar to that used in Gallup polls and in other research (Ditton et al. 2004). Assessments of safety or risk are potentially important components of fear (Warr 2000). Following Chiricos et al. (1997), the regression analyses examined respondents' perceptions of the crime rate. Two separate measures of the crime rate were used: U.S. crime rate and local crime rate. The respondents were asked to finish the statement: "The rate of crime in the United States [alternately, my area] seems to be ..." with a response of decreasing, staying the same, or increasing. Responses were coded so that -1 equaled decreasing, 0 equaled staying the same, and 1 equaled increasing.

Control variables used in the analyses included trust in sources of information about crime, prior victimization, and political ideology. The extent to which viewers trust the crime information transmitted by the media and government sources may influence how they interpret images seen on television. To control for this, trust information was assessed with two questions related to the reliability of information about crime: "How reliable is the media as a source of information about crime?" and "How reliable is the government 
as a source of information about crime?" Response categories ranged from 1 (not at all reliable) to 4 (very reliable). Kappeler and Potter (2005) asserted that the media and government work together to construct messages and images about crime. Factor analysis indicated that the two items did load on a single factor, so the responses to the two questions were averaged into an overall indicator of trust.

Victim was a dichotomous variable in which respondents answered yes or no to the question about whether they had been a victim of crime in the last year, and was coded so that 1 equaled yes. Political ideology may also impact people's attitudes about the justice system, independent of their media viewing. The control variable conservative was assessed with an item that asked respondents to rate themselves politically using a five-point scale. Following prior research on public attitudes toward the criminal justice system (Applegate et al. 2000; Unnever, Benson, and Cullen 2008), the variable was coded so that 1 was very liberal, and 5 was very conservative.

Audience characteristics may affect the relationship between media viewing and fear of crime (Chiricos et al. 1997). Accordingly, the regression analyses controlled for respondents' demographic characteristics, including age, education, race, sex, and residential location. Age and education were continuous variables measured in years. Race was a dummy variable with Nonwhite coded as 1 and white as reference category. Gender was a dummy variable with male coded as 1 . Respondents were asked to indicate their residential location as farm, open country, or town/city. Because of smaller frequencies relative to the town/city category, the response categories farm and open country were combined into rural. The dummy variable was coded so that 1 equaled town/city, and rural was the reference category.

\section{RESULTS}

Table 1 presents descriptive statistics for the sample. Chi-square tests were performed to determine if viewership varied by audience characteristics. Although the majority of respondents watched local news every day, those with more than a high school education watched local news more often $\left(\chi^{2}=23.71, p<.001\right)$. In addition, they watched national news slightly more often as well $\left(\chi^{2}=20.86, p<.01\right)$. Those with more education also watched nonfiction crime shows more often $\left(\chi^{2}=28.78, p<.001\right)$. There were no differences in viewing crime dramas by level of education.

Compared with those aged 35 and older, those aged 19-34 were significantly less likely to watch local $\left(\chi^{2}=64.41, p<.001\right)$ or national news $\left(\chi^{2}=61.71, p<.001\right)$ every day. There were no age differences in viewing either crime dramas or nonfiction crime shows. Women watched local news more often than men $\left(\chi^{2}=23.01, p<.01\right)$. They were also more likely to report watching crime dramas more frequently $\left(\chi^{2}=14.83, p<.05\right)$, but there were no sex differences in viewing nonfiction crime shows. White respondents reported viewing nonfiction crime shows slightly less often than nonwhite respondents $\left(\chi^{2}=15.87, p<.05\right)$. There were no racial differences in viewing the other program types. No residential location differences were noted in any of the viewership variables. 
Table 1. Descriptive Statistics for the Sample $(N=784)$

\begin{tabular}{lrrrr}
\hline Variables & Mean & SD & Range & $\alpha$ \\
\hline Age & 54.49 & 16.00 & $19-96$ \\
Education & 14.51 & 2.74 & $2-22$ \\
Nonwhite $=1$ & .05 & .22 & 0,1 \\
Male $=1$ & .41 & .49 & 0,1 \\
Town/city = & .81 & .39 & 0,1 \\
Conservative ideology & 3.33 & .89 & $1-5$ \\
Trust information & 1.22 & .55 & $0-3$ \\
Victim = 1 & .11 & .31 & 0,1 \\
Days watch local news & 5.41 & 2.22 & $0-7$ \\
Days watch national news & 4.38 & 2.56 & $0-7$ \\
Days watch TV crime dramas & 1.81 & 2.08 & $0-7$ \\
Days watch nonfiction crime & 1.42 & 1.76 & $0-7$ \\
Fear of crime & 1.29 & .71 & $0-4$ \\
U.S. crime rate & .57 & .62 & -1 to 1 \\
Local crime rate & .30 & .56 & -1 to 1 \\
Confidence in CJS & 1.37 & .49 & $0-3$ \\
Support death penalty $=1$ & .45 & .50 & 0,1 \\
\hline
\end{tabular}

CJS = Criminal Justice System

Table 2 presents correlations among the variables. Both frequency of viewing crime dramas and frequency of viewing nonfictional crime shows were positively correlated with fear of crime and support for the death penalty. Frequency of viewing nonfictional crime shows was negatively correlated with support for the criminal justice system; viewing crime dramas was unrelated. Fear was negatively correlated with confidence in the criminal justice system, but fear was unrelated to support for the death penalty. There was also a degree of correlation among all four of the viewership variables. In particular, the news viewership variables were highly correlated with each other, and crime drama and nonfiction program viewership variables were highly correlated with each other.

Table 3 presents OLS regressions on fear of crime and perceptions of the crime rate. Of the control variables, males were less likely to be fearful, and younger people and people who had been victims of crime in the previous year were more likely to be fearful. Of the viewership variables, only frequency of viewing nonfictional crime shows contributed to higher levels of fear. The other media variables were not statistically significant. Regarding perceptions of the U.S. crime rate, older people perceived the crime rate to be increasing. Males, people with higher levels of education, and people who trusted information sources thought the crime rate was decreasing. The media variables were not statistically significant. Regarding perceptions of the local crime rate, people who had been victims of crime in the previous year perceived the crime rate to be increasing. Males and people who trusted information sources thought the crime rate was decreasing. Of the viewership vari- 


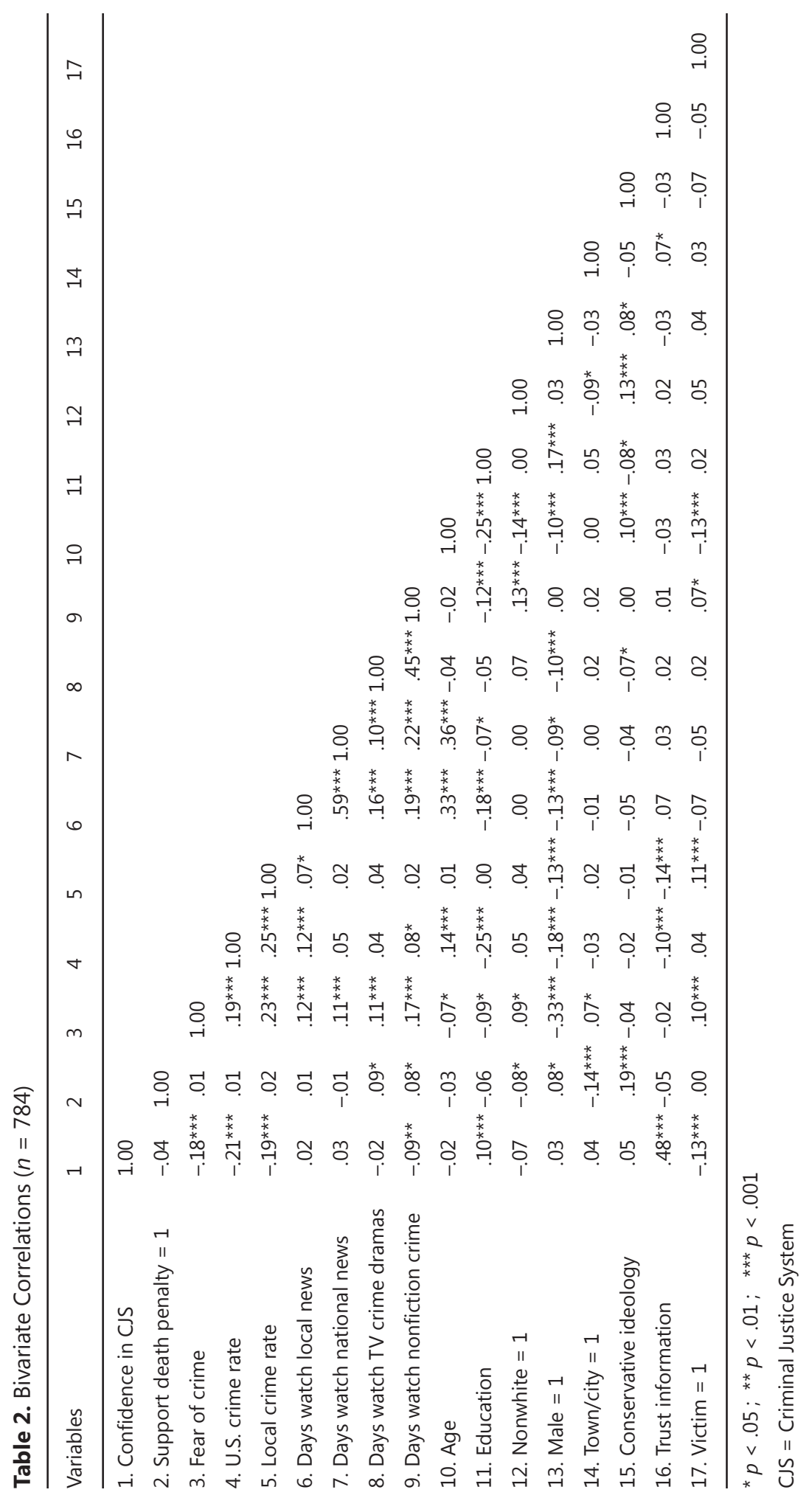




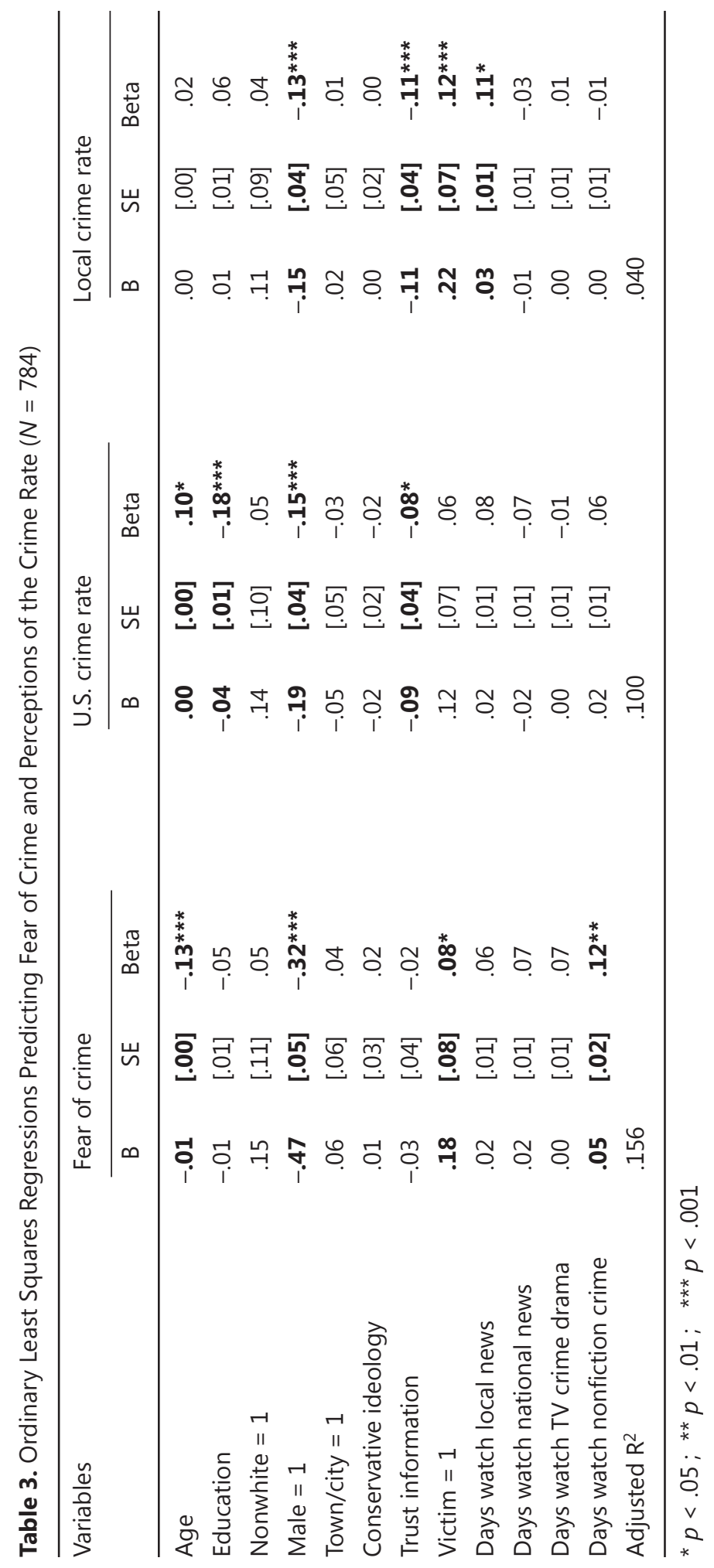


ables, only frequency of viewing local news predicted the perception that the local crime rate was increasing.

Table 4 presents OLS regressions on support for the criminal justice system. In model 1 , both education and trust in the government and media as sources of information positively predicted support for the justice system. On the other hand, people who experienced prior victimization were less supportive. Viewing crime dramas and news broadcasts was unrelated to support for the justice system, but viewing nonfictional crime shows contributed to less support. Although several interaction terms between the media variables were tested, none were statistically significant. In model 2 , fear was introduced into the regression. Fear entirely mediated the relationship between viewing nonfictional crime shows and support for the justice system. Higher levels of fear contributed to less support for the criminal justice system. In model 3, perceptions of U.S. and local crime rates were entered into the model. Fear remained statistically significant. People who perceived the U.S. crime rate to be increasing were less supportive of the justice system, but perceptions of the local crime rate were unrelated to support.

Table 5 presents logistic regressions on support for the death penalty. In model 1, town and city dwellers were less likely to support the death penalty, whereas those with a more conservative political ideology were more likely to support it. Unlike support for the criminal justice system, viewing nonfictional crime shows was unrelated to death penalty support, whereas viewing crime dramas predicted death penalty support. Each additional day of viewing crime dramas increased the odds of supporting the death penalty by 11 percent. Again, both news viewing variables were statistically no significant, and no interaction terms were significant. In model 2, fear was introduced into the regression, and in model 3, perceptions of the crime rate were introduced into the regression. Fear was unrelated to death penalty support, as were perceptions of the crime rate. These variables did not mediate the relationship between viewing crime dramas and death penalty support.

\section{DISCUSSION}

The results reveal a complex relationship among viewership patterns, fear of crime, and attitudes about the criminal justice system. Consistent with Curette's (1994) argument, the public audience appeared to negatively evaluate the criminal justice system while simultaneously supporting more punitive policies. The results presented here, which controlled for audience characteristics, indicate that this variation is due in part to the types of programs people watch. On the one hand, the more often people watched nonfictional crime programming, the more fearful they were of criminal victimization. Fear and the perception of an increasing national crime rate appeared to undermine their confidence in the ability of the criminal justice system to reduce crime, protect citizens, and treat them fairly. On the other hand, there was no significant relationship between viewing crime dramas and fear, yet the more often people watched crime dramas, the more likely they were to support the death penalty. Interestingly, when controlling 


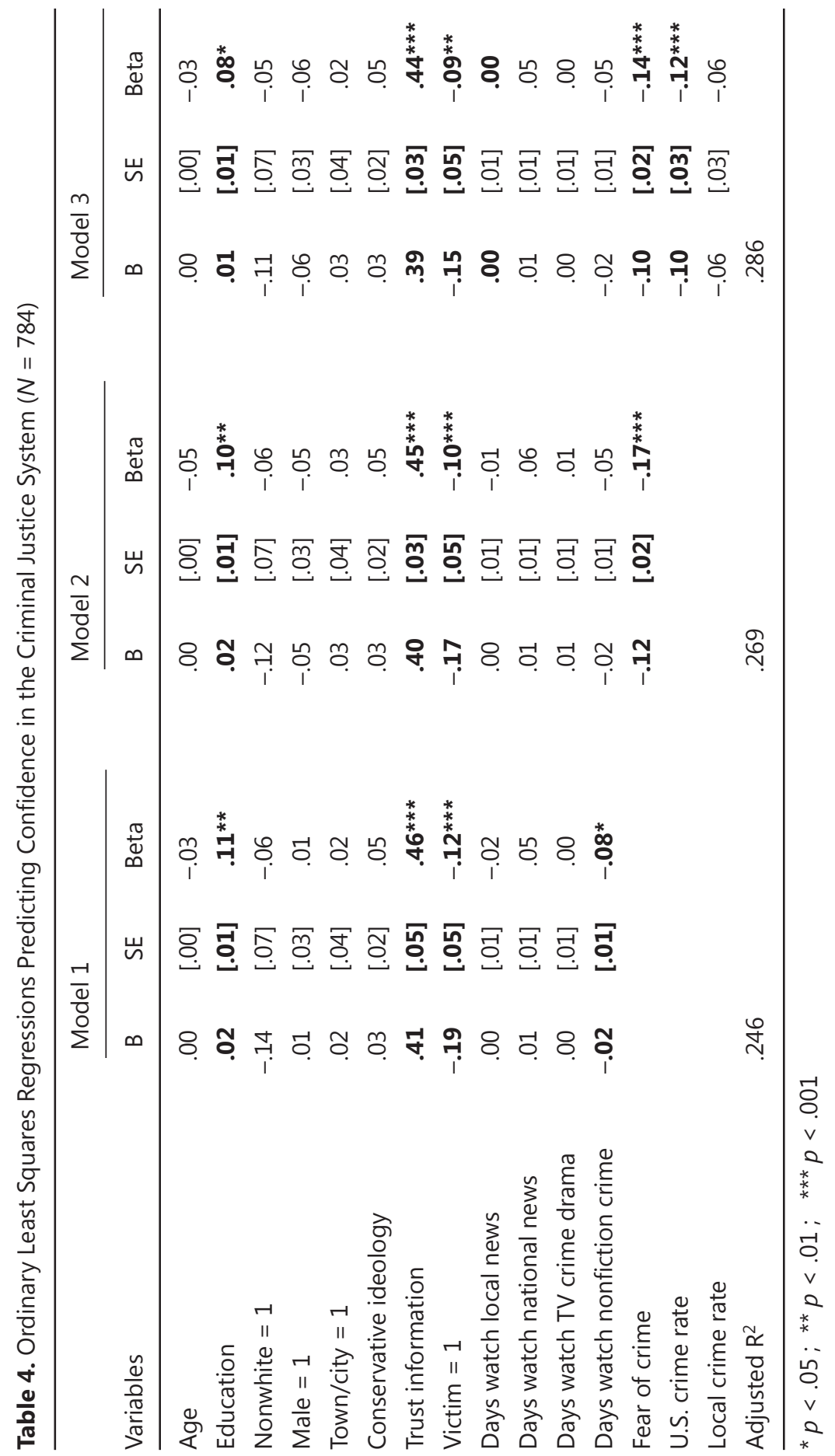




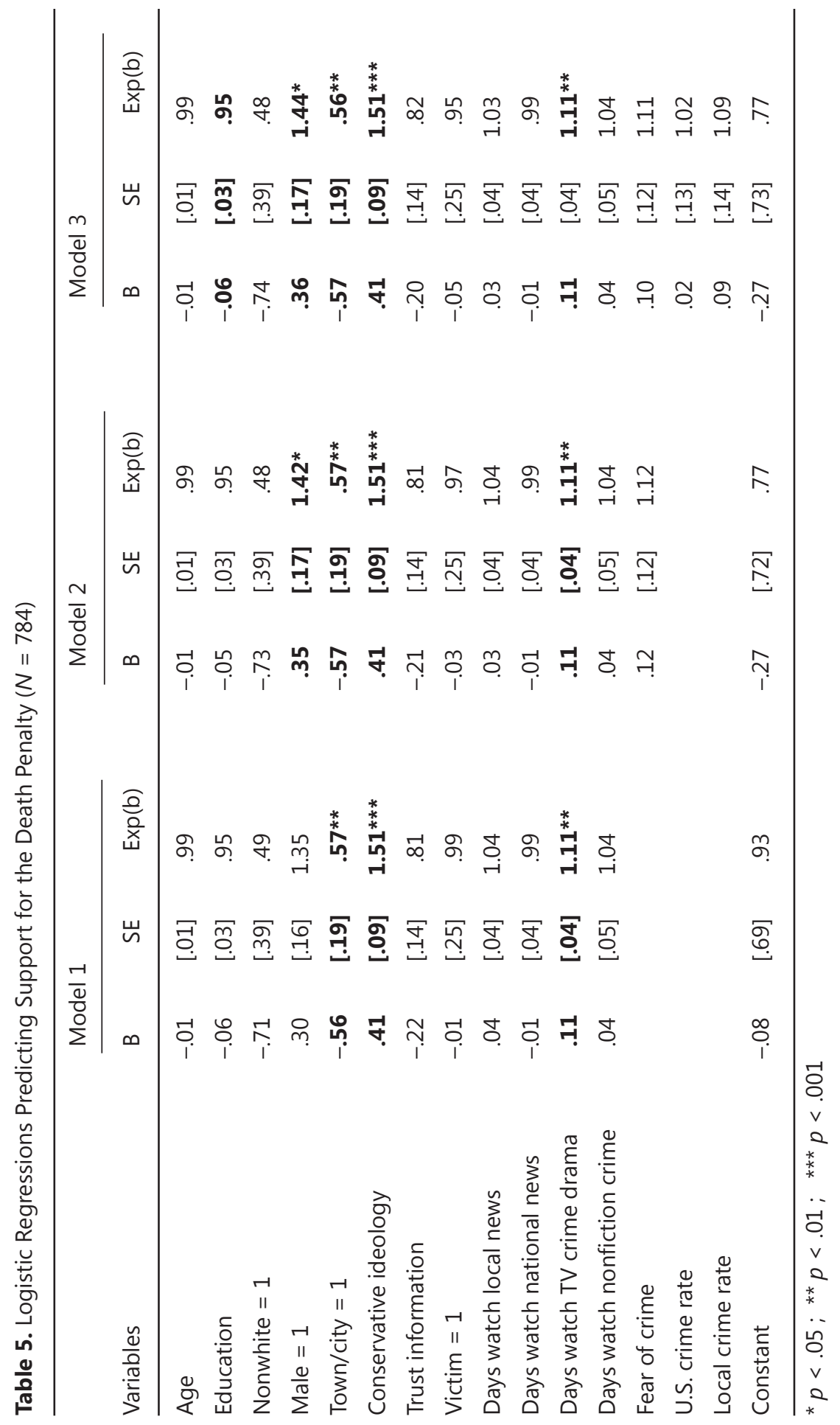


for audience characteristics and other viewership patterns, news viewership predicted neither fear of crime nor criminal justice attitudes.

Why should different kinds of programming result in different outcomes? When it comes to the portrayal of violence, both crime dramas and nonfictional crime programming focus on serious crimes. However, nonfictional programs by their nature offer more realism, and nonfictional images may simply have greater psychological impact than fictional ones (Kooistra, Mahoney, and Westervelt 1998). Moreover, in telling the story, nonfictional programs offer more context. Interviews with victims, their families, and friends can be manipulated to emphasize how the crime could happen to anyone, playing on fear for dramatic impact while increasing a sense of proximity. Whereas crime dramas are set in large cities, nonfictional programs are frequently set in smaller cities or suburban areas. Additionally, nonfictional programs often try to delve into the offender's personal history to explain his or her behavior, while highlighting his or her ability to evade detection by the authorities. Although the authorities may not be portrayed as incompetent, they always seem one step behind the offender. By comparison, crime dramas present cases in starker terms, portraying offenders as evil and the criminal justice system as moral authority, while providing less context for the offense and greater finality in case resolution (Eschholz et al. 2003; Cavender and Deutch 2007). Viewers of crime dramas can be assured that criminal justice personnel get the job done and the offender gets his or her just deserts.

Fear of crime entirely mediated the relationship between watching nonfictional television crime programs and support for the criminal justice system: the more fearful people were, the less supportive they were of the ability of the criminal justice system to deal with crime. This indicates that viewing nonfictional documentary programs about crime serves an infotainment function. These shows provide information about criminal events but can contribute to the idea that crime in the United States is out of control. Moreover, these shows also provide information on the challenges faced by the criminal justice system to deal with crime swiftly and fairly, all within an entertainment context that amplifies fear for dramatic effect.

Fear of crime was unrelated to support of the death penalty, as were perceptions of the crime rate. Identifying with a conservative political ideology, however, positively predicted support for the death penalty. This suggests that viewing television crime drama, which was also related to death penalty support, can serve an ideological function. The ideological undertones of crime dramas may be more relevant for policy support than these shows' ability to induce concern or fear about crime. In other words, to the extent that crime dramas disseminate and reinforce dominant ideological positions on crime and criminal justice through their focus on serious crime and just deserts, viewing such programs serves to maintain public support for the death penalty.

One reason that fear may be unrelated to death penalty support is that fear may not be the emotion people draw on when considering criminal justice options. According to Lyons and Scheingold (2000), "The anxieties associated with unwelcome social, economic, and cultural transformations generate anger, and punishment becomes a vehicle for that anger" (p. 127). Johnson (2009) found that anger about crime was positively re- 
lated to support for punitive policies, controlling for fear. The tidy endings of shows like "Law \& Order" allow viewers to leave the program without concerns that criminals are getting away with it and being released onto the streets (Gans-Boriskin and Wardle 2005). In short, viewers can take comfort that crime, in all its complexities, can be handled. Dramas emphasize that the social world seems increasingly complex and confusing, but dealing with crime via increasing punitiveness seems straightforward (Cavender 1998; Lyons and Scheingold 2000).

There were methodological limitations to this study. First, the survey was of a sample from one state, which is not necessarily representative of other populations. People in more urbanized states, more racially diverse states, more politically diverse states, and in states with objectively higher crime rates may have different perceptions of crime. On the other hand, because of their lower proximity and exposure to crime relative to other states, Nebraskans may be more reliant on the media as a source of information about crime. Future research should consider nationally representative samples to explore this topic in greater detail.

Second, there was only one item asking respondents about their viewership of nonfictional programming. Although the item prompted respondents to think about shows like those described above, respondents may have also had in mind reality shows like "COPS" or "America's Most Wanted." In the future, researchers should attempt to discriminate more completely among types of programming. Third, certain question formats could have influenced results. The viewership questions asked average viewing per week. A longer time frame, such as average viewing per month, may have included more respondents. Also, there was no question on total hours of viewing, which would have allowed for a statistical control to gauge proportion of time spent watching other kinds of programming. Fourth, it should be noted that viewership of each type of programming was strongly correlated, so that people who frequently watched one kind of program also watched the other. The format of the questions precluded our ability to separate fully the effect of one from another. Finally, the cross-sectional nature of the survey does not allow for statements of causality. Given the historical and ongoing saturation of crime in the media, it may be impossible to understand fully if media exposure has a causal impact on fear of crime and attitudes about criminal justice. Future researchers could consider quasiexperimental or longitudinal designs to assess the specificity and directionality of the relationships observed here.

Given these limitations, this study demonstrated, albeit conservatively, that what people watch on television matters when it comes to fear of crime and their attitudes about criminal justice. Crime-related programming shapes both personal fear of crime and the social response to crime (Kooistra et al. 1998). If there is a causal relationship between media consumption and fear of crime, the mechanisms by which media images influence people's perceptions about crime and criminal justice remain less understood (Heath and Gilbert 1996; Weitzer and Kubrin 2004). People who are fearful and/or who lack support for the criminal justice system may be disposed to watching certain kinds of programs, which may reinforce rather than bring about their anxieties and other attitudes. Others may watch crime programming for reassurance that justice ultimately triumphs when an 
offender is caught and convicted, reducing their fear while reinforcing their beliefs. Ditton et al's (2004) research indicated that understanding how the viewer perceives and interprets the media may be more relevant than measuring how much of certain kind of programming a person watches.

Future research should also consider a comparative content analysis of crime dramas and nonfictional documentary-style crime shows. Similar themes may be detected, but subtle differences in the portrayal of crime and justice may appear. For example, the opening credits of NBC's "Law and Order: SVU" state: "In the criminal justice system, sexually based offenses are considered especially heinous. In New York City, the dedicated detectives who investigate these vicious felonies are members of an elite squad known as the Special Victims Unit. These are their stories. "By comparison, a description of the program "Main Street Mysteries" aired on Investigation Discovery Channel (2010) reads: "Big crimes in small towns can cause fear and panic within tight-knit communities. Follow these small town investigators on mystifying cases to bring closure to the victims and their loved ones." Through such content analyses, especially if paired with research examining viewers' interpretations of different types of programs, we may gain a better understanding of why research on media consumption, fear of crime, and support for criminal justice policies has been equivocal. As the media continues to evolve, research must continue to explore why people view crime-related programming or access crime-related information, how they interpret it, and what impact it has on fear and other emotions, support for the criminal justice system, and criminal justice policies.

\section{REFERENCES}

A\&E Television. 2009. “The First 48.” Retrieved January 8, 2009, from http://www.aetv.com/the first 48/ about/

Altheide, David L. 1997. "The News Media, the Problem Frame, and the Production of Fear." The Sociological Quarterly 38:647-68.

—. 2009. "Moral Panic: From Sociological Concept to Public Discourse." Crime, Media, Culture 5:79-99.

Altheide, David L. and R. Sam Michalowski. 1999.“Fear in the News: A Discourse in Control.” The Sociological Quarterly 40:475-503.

Applegate, Brandon K., Francis T. Cullen, Bonnie S. Fisher, and Thomas Vander Ven. 2000. "Forgiveness and Fundamentalism: Reconsidering the Relationship between Correctional Attitudes and Religion." Criminology 38:719-54.

Barak, Gregg. 1994."Media, Society, and Criminology.” Pp. 3-48 in Media, Process, and the Social Construction of Crime: Studies in Newsmaking Criminology, edited by G. Barak. New York: Garland.

Barlow, Melissa Hickman, David E. Barlow, and Theodore G. Chiricos. 1995."Mobilizing Support for Social Control in a Declining Economy: Exploring Ideologies of Crime within Crime News." Crime and Delinquency 41:191-204.

Biography Channel. 2009. "Watching the Detectives." Retrieved January 8, 2009 from http://www.biography.com/video.do?name=watchingthedetectives\#about 
Cavender, Gray. 1998. "In 'The Shadow of Shadows': Television Reality Crime Programming.” Pp. 79-94 in Entertaining Crime, edited by M. Fishman and G. Cavender. New York: Aldine de Gruyter.

—. 2004. "Media and Crime Policy: A Reconsideration of David Garland's The Culture of Control." Punishment and Society 6:335-48.

Cavender, Gray and Lisa Bond-Maupin. 1993. "Fear and Loathing on Reality Television: An Analysis of 'America's Most Wanted' and 'Unsolved Mysteries.” Sociological Inquiry 63:305-17.

Cavender, Gray, Lisa Bond-Maupin, and Nancy C. Jurik. 1999. “The Construction of Gender in Reality Crime TV." Gender and Society 13:643-63.

Cavender, Gray and Sarah K. Deutch. 2007. "CSI and Moral Authority: The Police and Science." Crime, Media, Culture 3:67-81.

Cavender, Gray and Mark Fishman. 1998. "Television Reality Crime Programs: Context and History." Pp. 1-15 in Entertaining Crime, edited by M. Fishman and G. Cavender. New York: Aldine de Gruyter.

Chermak, Steven. 1994. "Crime in the News Media: A Refined Understanding of How Crimes Become News." Pp. 95-129 in Media, Process, and the Social Construction of Crime: Studies in Newsmaking Criminology, edited by G. Barak. New York: Garland.

Chiricos, Ted, Sarah Eschholz, and Marc Gertz. 1997.“Crime,News, and Fear of Crime: Toward an Identification of Audience Effects." Social Problems 44:342-57.

Chiricos, Ted, Kathy Padgett, and Marc Gertz. 2000. "Fear, TV News, and the Reality of Crime." Criminology 38:755-85.

Dahlgren, Peter. 1988. “What's the Meaning of This? Viewers' Plural Sense-Making of TV News." Media, Culture, and Society 10:285-301.

Ditton, Jason, Derek Chadee, Stephan Farrall, Elizabeth Gilchrist, and Jon Bannister. 2004. "From Imitation to Intimidation: A Note on the Curious and Changing Relationship between the Media, Crime, and Fear of Crime." British Journal of Criminology 44:595-610.

Donovon, Pamela. 1998. "Armed with the Power of Television: Reality Crime Programming and the Reconstruction of Law and Order in the United States." Pp. 117-37 in Entertaining Crime, edited by M. Fishman and G. Cavender. New York: Aldine de Gruyter.

Dowler, Kenneth. 2003."Media Consumption and Public Attitudes toward Crime and Justice: The Relationship between Fear of Crime, Punitive Attitudes, and Perceived Police Effectiveness." Journal of Criminal Justice and Popular Culture 10:109-26.

Doyle, Aaron. 1998. “'Cops': Television Policing as Policing Reality.” Pp. 95-116 Entertaining Crime, edited by M. Fishman and G. Cavender. New York: Aldine de Gruyter.

—. 2006."How Not to Think about Crime in the Media." Canadian Journal of Criminology and Criminal Justice 48:867-85.

Eschholz, Sarah. 1997. "The Media and Fear of Crime: A Survey of the Research." Journal of Law and Public Policy 9:37-59.

—. 2003. "Crime on Television-Issues in Criminal Justice." Journal of the Instituted of Justice and International Studies 2:9-18.

Eschholz, Sarah, Ted Chiricos, and Marc Gertz. 2003. "Television and Fear of Crime: Program Types, Audience Traits, and the Mediating Effect of Perceived Neighborhood Composition." Social Problems 50:395-415.

Eschholz, Sarah, Matthew Mallard, and Stacey Flynn. 2004. "Images of Prime Time Justice: A Content Analysis of 'NYPD Blue' and 'Law and Order." Journal of Criminal Justice and Popular Culture 10:161-80.

Gans-Boriskin, Rachel and Clair Wardle. 2005. "Mad or Bad? Negotiating the Boundaries of Mental Illness on 'Law and Order." Journal of Criminal Justice and Popular Culture 12:26-46. 
Gerbner, George. 1970."Cultural Indicators: The Case of Violence in Television Drama. "Annals of the American Academy of Political and Social Sciences 388:69-81.

Gerbner, George and L. Gross. 1976. "Living with Television: The Violence Profile." Journal of Communication 26:173-99.

Grabe, Maria Elizabeth and Dan G. Drew. 2007. "Crime Cultivation: Comparisons across Media Genres and Channels." Journal of Broadcasting and Electronic Media 51:147-71.

Heath, Linda and Kevin Gilbert. 1996. "Mass Media and Fear of Crime." American Behavioral Scientist 39:379-86.

Investigation Discovery Channel. 2010. "Main Street Mysteries.” Retrieved February 22, 2010; http://investigation.discovery.com/videos/main-street-mysteries/

Johnson, Devon. 2009. “Anger about Crime and Support for Punitive Criminal Justice Policies.” Punishment and Society 11:51-66.

Kappeler, Victor E. and Gary W. Potter. 2005. The Mythology of Crime and Criminal Justice. 4th ed. Long Grove, IL: Waveland Press.

Kooistra, Paul G., John S. Mahoney, and Saundra D. Westervelt. 1998. "The World of Crime According to 'Cops."' Pp. 141-58 in Entertaining Crime, edited by M. Fishman and G. Cavender. New York: Aldine de Gruyter.

Lowry, Dennis T., Tarn Ching Josephine Nio, and Dennis W. Leitner. 2003."Setting the Public Fear Agenda: A Longitudinal Analysis of Network TV Crime Reporting, Public Perceptions of Crime, and FBI Crime Statistics." Journal of Communication 53:61-73.

Lyons, William and Stuart Scheingold. 2000. “The Politics of Crime and Punishment." Pp. 103-49 in The Nature of Crime: Continuity and Change, Criminal Justice 2000, vol. 1, edited by G. LaFree. Washington, DC: United States Department of Justice.

Sacco, Vincent. 1995. "Media Constructions of Crime." Annals of the American Academy of Political and Social Sciences 539:141-54.

Signorielli, Nancy, George Gerbner, and Michael Morgan. 1995. "Standpoint: Violence on Television: The Cultural Indicators Project." Journal of Broadcasting and Electronic Media 39:278-83.

Surette, Ray. 1994. "Predator Criminals as Media Icons." Pp. 131-58 in Media, Process, and the Social Construction of Crime: Studies in Newsmaking Criminology, edited by G. Barak. New York: Garland.

—. 1998.Media, Crime, and Criminal Justice: Images and Realities, edited by T. Clear. Belmont, CA: West/Wadsworth.

—. 2003."TheMedia, the Public, and Criminal Justice Policy." Journal of the Institution of Justice and International Studies 2:39-52.

Unnever, James D., Michael L. Benson, and Francis T. Cullen. 2008. "Public Support for Getting Tough on Corporate Crime." Journal of Research in Crime and Delinquency 45:163-90.

Warr, Mark. 2000. "Fear of Crime in the United States: Avenues for Research and Policy." Vol. 4, Pp. 451-89 in Measurement and Analysis of Crime and Justice, Criminal Justice 2000, edited by D. Duffee. Washington, DC: United States Department of Justice.

Weitzer, Ronald and Charis E. Kubrin. 2004. "Breaking News: How Local TV News and Real-World Conditions Affect Fear of Crime." Justice Quarterly 21:497-520. 